\title{
Variation in ultraviolet radiation and diabetes: evidence of an epigenetic effect that modulates diabetics' lifespan
}

\author{
George E Davis Jr ${ }^{*}$ and Walter E Lowell
}

\begin{abstract}
Background: Published research has shown that month-of-birth variations modulate the incidence of adult human diseases. This article explores diabetes type 2 as one of those diseases. This study uses the death records of approximately 829,000 diabetics (approximately 90\% were type-2) born before the year 1945 (and dying between 1979 and 2005) to show that variations in adult lifespan vary with ultraviolet radiation (UVR) at solar cycle peaks (MAX, approximately a three-year period) with less at non-peaks (MIN, approximately an eight-year period). The MAX minus MIN (in years) was our measure of sensitivity (for example, responsiveness) to long-term variations in UVR.

Results: Diabetics were less sensitive than non-diabetics, and ethnic minorities were more sensitive than whites. Diabetic males gained 6.1 years, and females 2.3 years over non-diabetics, with diabetic males gaining an average of 3.8 years over diabetic females. Most variation in lifespan occurred in those conceived around the seasonal equinoxes, suggesting that the human epigenome at conception is especially influenced by rapid variation in UVR. With rapidly decreasing UVR at conception, lifespan decreased in the better-nourished, white, female diabetic population.

Conclusions: Rapidly changing UVR at the equinoxes modulates the expression of an epigenome involving the conservation of energy, a mechanism especially canalized in women. Decreasing UVR at conception and early gestation stimulates energy conservation in persons we consider 'diabetic' in today's environment of caloric surfeit. In the late 19th and early 20th centuries ethnic minorities had poorer nutrition, laborious work, and leaner bodies, and in that environment a calorie-conserving epigenome was a survival advantage. Ethnic minorities with a similar epigenome lived long enough to express diabetes as we define it today and exceeded the lifespan of their nondiabetic contemporaries, while that epigenome in diabetics in the nutritional environment of today is detrimental to lifespan.
\end{abstract}

Keywords: solar cycles, seasonality, type 2 diabetes, epigenome, UVR, ultraviolet radiation, lifespan, month of conception

\section{Background}

Diabetes is a manifestation of the failure of the body to manage carbohydrate intake with aging and increased body weight. Over the past forty years there has been a progressive decrease in the defined upper limits of normal for fasting blood glucose categorizing more persons as diabetic, but even considering this changing diagnostic threshold there is a worldwide increase in the incidence and prevalence of diabetes mellitus, particularly type-2 diabetes [1-3]. Epigenetic mechanisms are likely

\footnotetext{
* Correspondence: georgedavi@gmail.com

Psybernetics Research Group, 28 Eastern Ave., Augusta, ME 04330, USA
}

involved, especially in the third world where obesity is a major, but not the only factor [4]. There are a wide variety of potential modulators of the human epigenome, which can be modified through methylation, Xinactivation, maternal imprinting, and microRNAs, as well as by environmental chemicals, toxins, caloric intake and dietary sugars [5-9]. In type-2 diabetes the early effects of maternal nutrition and exposure to carbohydrates may 'set' a course for adult disease [10-15]. Studies report that the nutrition of grandparents has been shown to affect future generations, particularly the male probands [8,16-19]. However, the most important modifying factors in type- 2 diabetes in adults are excess caloric

\section{() Biomed Central}

(c) 2013 Davis and Lowell; licensee BioMed Central Ltd. This is an Open Access article distributed under the terms of the Creative Commons Attribution License (http://creativecommons.org/licenses/by/2.0), which permits unrestricted use, distribution, and reproduction in any medium, provided the original work is properly cited. 
intake and decreased physical exercise. The Canadian Institutes of Health Research estimates that a North American child born in the year 2000 has one chance in three of being diabetic in his/her lifetime. The lifetime expenses associated with this diagnosis are considerable, and with a 'baby boomer' generation manifesting more diabetes as it ages, the societal cost for this metabolic disease in the United States will triple by the year 2034 [20,21].

Although type- 2 diabetes is pathological in our current environment of surfeit, we hypothesize the disease is a manifestation of an ancient survival mechanism, for example, a manifestation of the ability of the human species to conservatively store and efficiently metabolize calories in times of hardship. In addition, we propose that those afflicted with type- 2 diabetes are manifesting the epigenetic changes due to lifestyle (insufficient exercise, excess sugars), as well as by aging and genetic loading.

Our previous research has shown that changes in solar radiation, as seen in 11-year solar cycles, influence human lifespan [22]. The Sun varies in its radiation with approximately three years of more intense output (MAX) followed by approximately eight years of less radiation (MIN). We have shown in a study of death records of over 50 million persons in the USA that lifespan is decreased by 1.7 years on average in persons born and likely conceived at MAX of solar cycles [23]. We proposed that this finding may be due to the increased exposure of our genome to ultraviolet radiation
(UVR), the most DNA-damaging wavelength reaching the Earth's surface [24]. In our previously reported research we found that metabolic diseases, like diabetes, were suppressed during solar MAX relative to MIN; conversely, we found that major mental illness was more likely in those born during solar MAX $[25,26]$. In this paper we specifically investigate the modulation of lifespan of persons with type- 2 diabetes with changes in the 11-year solar radiation cycle and seasonal variations in UVR.

\section{Results}

We consider [MAX - MIN] for lifespan a metric for sensitivity (for example, responsiveness) to long-term changes in UVR. Figure 1 shows that the difference in lifespan between MAX and MIN is less in diabetes than in nondiabetics. In addition, ethnic minorities have a higher sensitivity, for example, a greater difference between MAX and MIN, than the white race. Also, females are generally less sensitive than males in their respective racial groups. Figure 2 (for males) and Figure 3 (for females) are examples from a single bimonthly period (March and April) plotting the difference between diabetic and non-diabetic lifespan at MAX versus at MIN for all racial groups. Note that the white and white Canadian group diabetic females in Figure 3 had a shorter lifespan than non-diabetics. This is similar to what we would see in today's environment of surfeit in contrast to the ethnic minorities born largely before 1945.

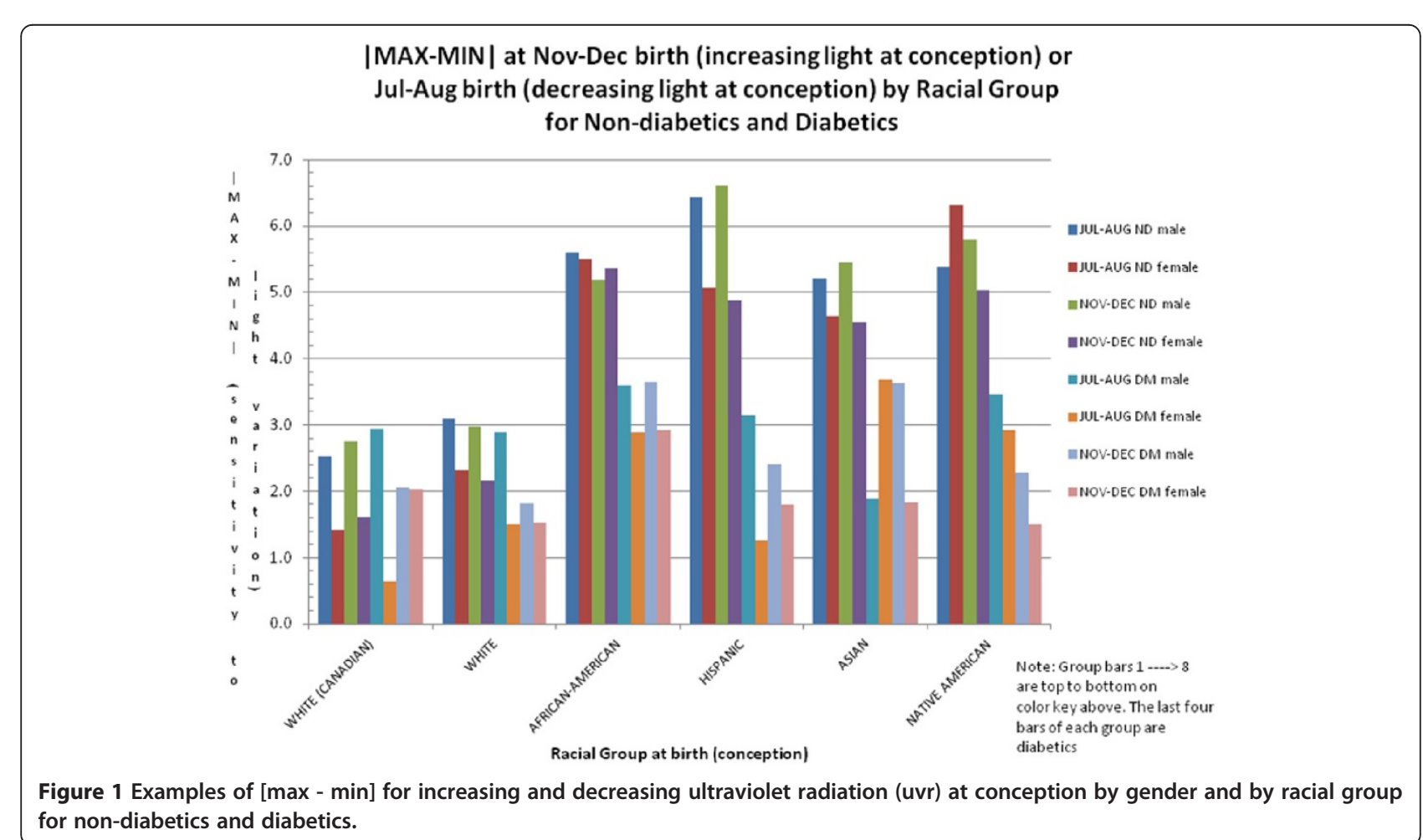



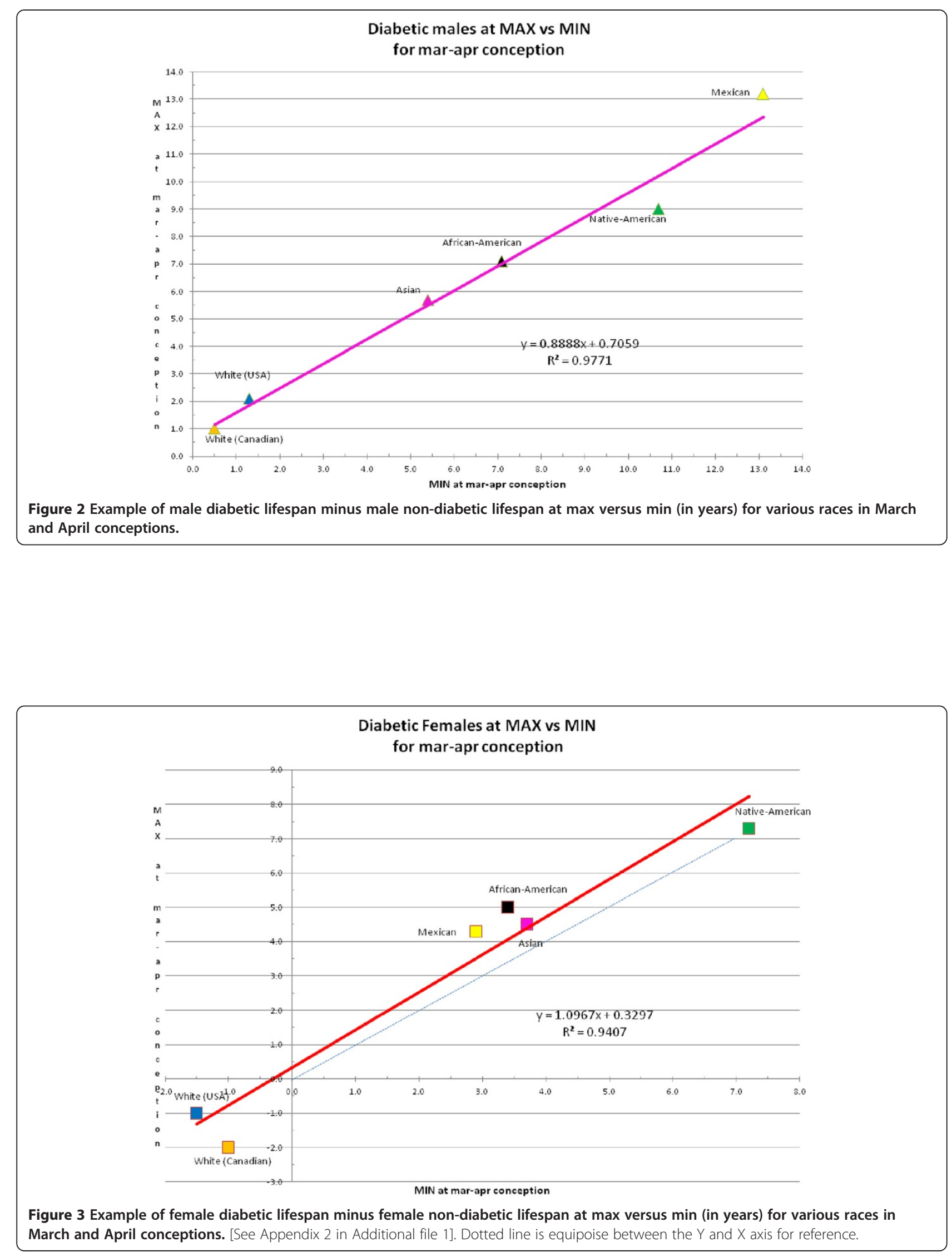
As displayed at the bottom of Table 1 for MAX and Table 2 for MIN, the average years gained for males at MAX with increasing seasonal light at conception is greater than with decreasing seasonal light, and although there is more variation with females at MAX, there is little difference between the averages at increasing or decreasing light. At MIN however, males gain significantly more years above females when conceived in decreasing light.

Data in Tables 1 and 2 for annual years of life gained are used in calculations resulting in Table 3, and subsequently, Table 4 (see Methods). For the convenience of the reader, month of birth (MOB) is easily converted to month of conception (MOC) by simply adding three months to the MOB; for example, a May birth has an August MOC.

Figure 4 displays the monthly data from Tables 1 and 2 showing that most of the variation in lifespan occurs at the equinoxes when UVR varies the most rapidly. Note in Figure 4 that males have a bilobed pattern for MAX and MIN at the fall equinox while females have a single lobe. Both males and females have a single lobe at the spring equinox. The reason for these differences is not clear. The least variation in lifespan occurs at the solstices in both genders. We found that the weighted (72\% MIN and 28\% MAX) average lifespan years gained by male diabetics over male non-diabetics was 6.1 years [see Appendix 2 in Additional file 1], whereas that difference in females was only 2.3 years. Therefore, diabetic males gained $(6.1-2.3=) 3.8$ years over diabetic females on average.

The complexity of this study is related to several overlapping variables that include:

1) UVR intensity and variation $\rightarrow$ where variation is likely more important than intensity in activating diabetes.

2) Seasons and solar cycles $\rightarrow$ where seasons appear more important than solar cycle variation in affecting diabetes, but appear to be independent of vitamin D (see Discussion).

3) Being conceived and likely born before 1945 or after $1945 \rightarrow$ nutritional environments change from poorer nutrition to caloric excess between the two periods.

4) Diabetics and non-diabetics $\rightarrow$ in times of hardship persons who live longer are more likely to express diabetes (from aging itself); in times of plenty diabetics live shorter lives.

5) Whites and ethnic minorities $\rightarrow$ the more melanin, the more sensitive to changes in solar cycle UVR; for example, long-term changes are more important than short-term (seasonal) changes (see Figure 1).

Table 1 Male and female diabetics - regression equations and integral values at solar MAX

\begin{tabular}{|c|c|c|c|c|c|}
\hline $\begin{array}{l}\text { Month of } \\
\text { conception } \\
\text { (All races) }\end{array}$ & $\begin{array}{l}\text { Male diabetics } \\
\text { regression } E Q \\
\text { and }\left(R^{2}\right) \text { at } M A X\end{array}$ & $\begin{array}{l}\text { Integral of MAX } \\
\text { years for MIN }\end{array}$ & $\begin{array}{l}\text { Female diabetics } \\
\text { regression } E Q \\
\text { and }\left(R^{2}\right) \text { at } M A X\end{array}$ & $\begin{array}{l}\text { Integral of MAX } \\
\text { years for MIN }\end{array}$ & $\begin{array}{l}\text { Month of birth } \\
\text { (All races) }\end{array}$ \\
\hline & & $\begin{array}{c}-5.0 \text { to } 10.0 \\
\text { (males) }\end{array}$ & & $\begin{array}{c}-5.0 \text { to } 10.0 \\
\text { (females) }\end{array}$ & \\
\hline Jan-Feb & $1.0663 x+0.0928(0.9722)$ & 41.4 & $1.1427 x+0.1749(0.9590)$ & 45.5 & Oct-Nov \\
\hline Feb-Mar & $1.3704 x+0.5432(0.9672)$ & 59.5 & $1.3820 x+1.6371(0.9902)$ & 76.4 & Nov-Dec \\
\hline Mar-Apr & $0.8888 x+0.7059(0.9771)$ & 43.9 & $1.0967 x+0.3297(0.9407)$ & 46.1 & Dec-Jan \\
\hline Apr-May & $0.9180 x+0.8914(0.9964)$ & 47.8 & $1.2347 x-0.0794(0.9795)$ & 45.1 & Jan-Feb \\
\hline May-Jun & $0.9499 x+1.0587(0.9846)$ & 51.5 & $1.122 x-0.1454(0.9414)$ & 39.9 & Feb-Mar \\
\hline Jun-Jul & $1.067 x-0.3400(0.9844)$ & 34.9 & $1.0969 x-0.0983(0.9213)$ & 39.7 & Mar-Apr \\
\hline Jul-Aug & $1.0918 x-0.8685(0.9677)$ & 27.9 & $0.6996 x+1.5517(0.9797)$ & 49.5 & Apr-May \\
\hline Aug-Sep & $1.0383 x-0.2481(0.9913)$ & 35.2 & $1.0984 x+0.5254(0.9656)$ & 49.1 & May-Jun \\
\hline Sep-Oct & $1.0019 x+0.1545(0.9820)$ & 39.9 & $1.0736 x+1.0948(0.9689)$ & 56.7 & Jun-Jul \\
\hline Oct-Nov & $1.2887 x+0.3252(0.9787)$ & 53.2 & $1.2419 x+1.6821(0.9228)$ & 71.8 & Jul-Aug \\
\hline Nov-Dec & $0.9303 x-0.1257(0.9508)$ & 33.0 & $0.9222 x+0.0196(0.9566)$ & 34.9 & Aug-Sep \\
\hline Dec-Jan & $0.8933 x+0.2413(0.9077)$ & 37.1 & $0.8859 x+0.4906(0.9375)$ & 40.6 & Sep-Oct \\
\hline Average & & 42.1 & & 49.6 & \\
\hline Sum & & 505.3 & & 595.3 & \\
\hline SD & & 9.4 & & 12.8 & \\
\hline AVG (SD) years Increasing & & $46.5(8.5)$ & & 48.7 (13.8) & \\
\hline AVG (SD) years Decreasing & & $37.7(8.6)$ & & $50.4(12.9)$ & \\
\hline
\end{tabular}


Table 2 Male and female diabetics - regression equations and integral values at solar MIN

\begin{tabular}{|c|c|c|c|c|c|}
\hline $\begin{array}{l}\text { Month of conception } \\
\text { (All races) }\end{array}$ & $\begin{array}{l}\text { Male diabetics } \\
\text { regression EQ } \\
\text { and }\left(\mathrm{R}^{2}\right) \text { at } \mathrm{MIN}\end{array}$ & $\begin{array}{c}\text { Integral of MIN } \\
\text { years for MAX } \\
-5.0 \text { to } 10.0 \text { (males) }\end{array}$ & $\begin{array}{l}\text { Female diabetics } \\
\text { regression EQ } \\
\text { and }\left(R^{2}\right) \text { at MIN }\end{array}$ & $\begin{array}{c}\text { Integral of MIN } \\
\text { years for MAX } \\
-5.0 \text { to } 10.0 \text { (females) }\end{array}$ & $\begin{array}{l}\text { Month of birth } \\
\text { (All races) }\end{array}$ \\
\hline Jan-Feb & $0.9117 x+0.0927(0.9722)$ & 35.6 & $0.8392 x-0.0337(0.9590)$ & 31.0 & Oct-Nov \\
\hline Feb-Mar & $0.7058 x-0.2250(0.9672)$ & 23.1 & $0.7165 x-1.1636(0.9902)$ & 9.4 & Nov-Dec \\
\hline Mar-Apr & $1.0993 x-0.6305(0.9771)$ & 31.8 & $0.8577 x-0.1375(0.9407)$ & 30.1 & Dec-Jan \\
\hline Apr-May & $1.0854 x-0.9453(0.9964)$ & 26.5 & $0.7933 x+0.1134(0.9795)$ & 31.4 & Jan-Feb \\
\hline May-Jun & $1.0365 x-1.0068(0.9846)$ & 23.8 & $0.8391 x+0.2486(0.9414)$ & 35.2 & Feb-Mar \\
\hline Jun-Jul & $0.9225 x+0.4064(0.9844)$ & 40.7 & $0.8399 x+0.2315(0.9213)$ & 35.0 & Mar-Apr \\
\hline Jul-Aug & $0.8864 x+0.9662(0.9677)$ & 47.7 & $0.9144 x+0.0114(0.9655)$ & 34.5 & Apr-May \\
\hline Aug-Sep & $0.9547 x+0.2916(0.9913)$ & 40.2 & $0.8791 x-0.3822(0.9656)$ & 27.2 & May-Jun \\
\hline Sep-Oct & $0.9801 x-0.0377(0.9820)$ & 36.2 & $0.9026 x-0.9296(0.9689)$ & 19.9 & Jun-Jul \\
\hline Oct-Nov & $0.7594 x-0.1394(0.9787)$ & 26.4 & $0.7431 x-1.1432(0.9228)$ & 10.7 & Jul-Aug \\
\hline Nov-Dec & $1.022 x+0.4609(0.9508)$ & 45.2 & $1.0463 x-0.1893(0.9749)$ & 36.4 & Aug-Sep \\
\hline Dec-Jan & $1.0161 x+0.3772(0.9077)$ & 43.8 & $1.0582 x-0.3498(0.9375)$ & 34.4 & Sep-Oct \\
\hline Average & & 35.1 & & 27.9 & \\
\hline Sum & & 421 & & 335 & \\
\hline SD & & 8.7 & & 9.5 & \\
\hline AVG (SD) years Increasing & & $30.3(7.0)$ & & $28.7(9.7)$ & \\
\hline AVG (SD) years Decreasing & & $39.9(7.7)$ & & $27.2(10.2)$ & \\
\hline
\end{tabular}

Note: Italics for months with increasing UVR.

6) Males and females $\rightarrow$ males are more sensitive to variation in UVR; women are more canalized with regard to caloric retention and are less sensitive.

Table 5 concisely summarizes these relationships.

\section{Discussion}

This paper presents evidence that UVR, which varies in intensity with solar cycles and seasons, modulates the lifespan of type-2 diabetics born before 1945 . Using the death records of approximately 829,000 diabetics born before 1945 , we found that ethnic minority diabetics lived significantly longer than their non-diabetic minority contemporaries. In contrast, in the last decades of the 20th century

Table 3 Calculations using values from Tables 1 and 2

\begin{tabular}{lc}
\hline For the MAX portion of solar cycles & Years \\
Diabetic males at MAX in increasing UVR & 241.8 \\
Diabetic males at MAX in decreasing UVR & 189.5 \\
Diabetic females at MAX in increasing UVR & 253.1 \\
Diabetic females at MAX in decreasing UVR & 262.8 \\
For the MIN portion of solar cycles & Years \\
Diabetic males at MIN in increasing UVR & 144.0 \\
Diabetic males at MIN in decreasing UVR & 195.0 \\
Diabetic females at MIN in increasing UVR & 137.0 \\
Diabetic females at MIN in decreasing UVR & 128.5 \\
\hline
\end{tabular}

Native Americans with a high prevalence of obesity and diabetes have a shorter lifespan [27]. However, the white diabetic females born prior to 1945 revealed what we would expect today, for example, shorter lives most probably due to vascular complications. We suspect that the difference in lifespan between whites and ethnic minorities was due to poorer nutrition and hard physical work in the latter groups; indeed, most of human history was a continuous struggle to obtain food [28]. Many ethnic minorities had fled from famine in Europe and Asia and took laborious jobs in the United States, but despite the USA being 'a land of plenty', nutrition was a significant problem manifested by pellagra (niacin deficiency) at least through the 1940s [29].

Those with epigenetic alterations to increase metabolic efficiency and caloric storage would have a survival advantage in an adverse environment. While the huntergatherers of pre-historical humans generally had adequate nutrition, throughout human history there have been periodic famines in all continents with, in some cases, the loss of millions of lives [30-33]. In our study ethnic minorities, had a modest caloric intake readily metabolized by hard physical labor [34,35]. As discussed by Lane, people for the last 6,000 years have struggled to get something to eat, and even in modern times many in the world go without adequate nutrition [28]. Obesity was subsequently less prevalent than in the post 1950 to the present era. 
Table 4 Calculations using values from Table $\mathbf{3}$

\begin{tabular}{|c|c|}
\hline $\begin{array}{l}\text { For decreasing UVR at } \\
\text { conception }\end{array}$ & $\begin{array}{c}\text { Ratio years gained at MAX by male } \\
\text { diabetics/female diabetics }\end{array}$ \\
\hline \multirow[t]{2}{*}{$189.5 / 262.8=$} & 0.72 \\
\hline & $\begin{array}{c}\text { Ratio years gained at MIN by male } \\
\text { diabetics/female diabetics }\end{array}$ \\
\hline $195.0 / 128.5=$ & 1.52 \\
\hline $\begin{array}{l}\text { For increasing UVR at } \\
\text { conception }\end{array}$ & $\begin{array}{c}\text { Ratio years gained at MAX by male } \\
\text { diabetics/female diabetics }\end{array}$ \\
\hline \multirow[t]{2}{*}{$241.8 / 253.1=$} & 0.96 \\
\hline & $\begin{array}{l}\text { Ratio years gained at MIN by male } \\
\text { diabetics/female diabetics }\end{array}$ \\
\hline $144.0 / 137.0=$ & 1.05 \\
\hline
\end{tabular}

There is increasing evidence that early life events have effects that modulate the adult expression of disease. We hypothesize that rapidly changing UVR is most influential at conception/early gestation, particularly at the equinoxes, and alters epigenetic expression in diabetes. Rapidly decreasing UVR at conception, for example, at the autumnal equinox, was disadvantageous to the white race (and those in other races of higher social status) possibly because of good nutrition and less physically demanding jobs where activation of 'frugal' epigenes only predisposes to obesity [36]. Women in general are at a particular disadvantage probably due to a canalized tendency to retain weight for pregnancy and due to the effect of estrogens; however, rapidly increasing UVR at conception, for example, at or around the vernal equinox, may be beneficial to women due to the suppression of a calorie-conservative epigenome and may also be useful to men who are genetically predisposed to become overweight or who are underactive. A Ukrainian study has recently showed that type 2 diabetes is more common in those born in April (for example, conception in July with decreasing UVR), and is less common in those born in November and December (for example, conception in February and March with increasing UVR) [37].

The above observations suggest that increased skin melanin is associated with an increased sensitivity to ambient UVR as seen in Figure 1. One might have expected the reverse. However, melanin is an adaptation to increased UVR intensity, and more sensitivity to any variation in UVR may be necessary and encoded in the human genome over millennia [24].

One can speculate about how UVR affects an embryo in utero without direct exposure to UVR. A comprehensive review of how the skin senses the environment was recently published [38]. With the skin sharing an ectodermal origin with the central nervous system, it is not surprising to find shared neuroregulatory compounds in both tissues, including serotonergic, melatoninergic, catacholinergic, opioidergic, and the hormone vitamin D, among several others. Circulating inflammatory cytokines, chemokines, photo-oxidation products, and nitric oxide may also play a role [39-41].

There are recent reports that hypovitaminosis $\mathrm{D}$ is associated with a higher incidence of diabetes [42-44]. This is especially true for those with more skin pigmentation [45]. Those persons working in agrarian jobs would spend much more time outdoors, and by increasing their vitamin D level, could mitigate or

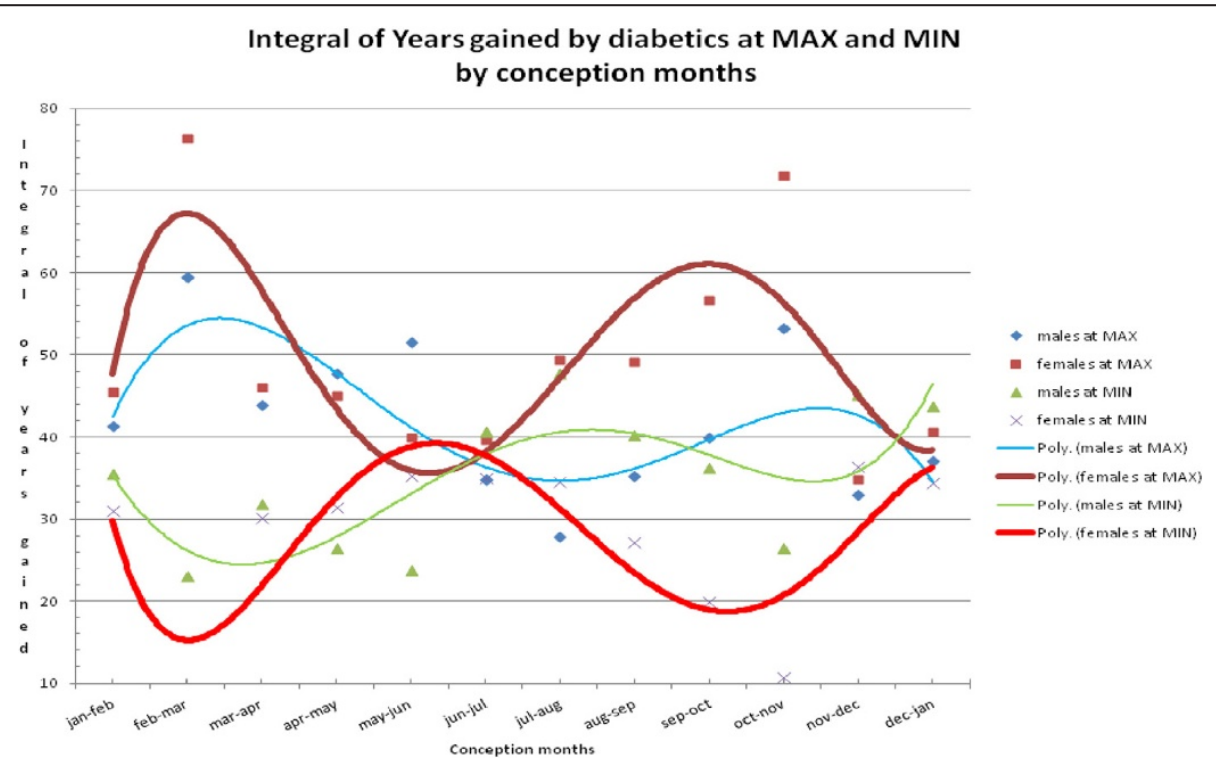

Figure 4 Trend lines of integral years gained by gender at max and min by months of conception for diabetics who were born before year 1945. poly, 3rd degree polynomial trend lines of data from Tables 1 and 2 for male and female diabetics. 
Table 5 Summary of findings related to ultraviolet radiation (uvr) variations

\begin{tabular}{ll}
\hline Lower sensitivity (smaller MAX - MIN) & Higher sensitivity (larger MAX - MIN) \\
\hline Diabetics & Non-diabetics \\
More genetic & More epigenetic \\
White race & Ethnic minority races \\
Ethnic minority diabetics & Ethnic minority non-diabetics \\
Female ethnic minority diabetics & Male ethnic minority diabetics \\
$\begin{array}{ll}\text { Diabetic females less affected by seasonal changes in UVR, slightly benefit } \\
\text { at MAX }\end{array}$ & Diabetic males benefit by decreasing seasonal UVR at conception, and \\
\hline
\end{tabular}

delay the expression of diabetes. The literature supports adequate vitamin $\mathrm{D}$ increasing insulin sensitivity [46]. This may be an additional reason for the greater lifespan of those with diabetes around the turn of the last century as well as greater physical activity and less obesity. Vitamin D is important in modifying a human epigenome involved with many adult disorders [47]. However, as Figure 4 shows, in this study of our cohort of diabetics there is no difference between the summer and winter solstice in added life years and the major variation in lifespan occurs at the equinoxes. Any effect of vitamin D on lifespan would therefore extend beyond the annual seasonal cycle. Variations in food supply occurring cyclically over years, would give a survival advantage to those individuals with an increased ability to store calories and vitamin $\mathrm{D}$ in adipose tissue.

The heterogeneity of our sample results in some persons that benefit, and some who are harmed, by activating or suppressing the metabolically sensitive epigenome, as is evident in Figure 4. Table 5 summarizes observations from Tables 1 and 2 .

We are aware that type- 2 diabetes is a heterogeneous disease affecting many organ systems and contributing to death in a various ways. However, we wanted to study specifically how UVR affects lifespan, not any other clinical aspects of this disease. Separating the effects of long-term solar-cycle radiation from that of seasonal (annual) radiation was challenging. We also probably did not detect more than one-third of the diabetics in our database, but for those who were captured, diabetes must have played a significant role to be entered on a death certificate, and therefore, these cases were likely to be the most severe.

We do not have comparable death data of persons who were born and died post-1945, and another halfcentury will pass before that data are available. However, it is already clear that there is an epidemic of type- 2 diabetes worldwide. Women are particularly adversely affected in our current environment $[48,49]$. As we have shown, diabetic white women were losing lifespan even before 1945. Some of these findings are obviously due to a rising standard-of-living in highly developed countries, for example, better food supplies and an increased use of mechanical devices in lieu of manual labor.

Reports suggest that white race northern Europeans may have developed a partial resistance to diabetes over the centuries, becoming adapted to a lactose-rich diet through farming/animal husbandry, and to rapidly changing light at higher latitude through natural selection [50,51].

Migration is probably another important factor in the increasing incidence of type- 2 diabetes. People who are indigenous to a high-intensity, low-variation photonic environment, like those born near or on the Equator, who then migrate to higher latitude, may be more susceptible to the trigger of decreasing UVR at conception (especially at the autumnal equinox), and along with a nutrient-rich lifestyle, more readily acquire type- 2 diabetes. This may explain, in part, the increased prevalence of type-2 diabetes in immigrants to northern Europe and to North America [52]. Once adjusted for ethnicity and socio-demographic variables, migration alone may not be crucial to health outcomes [53]. This opens the possibility that other factors, yet to be fully studied, like solar cycle variations of UVR and geomagnetic forces, modulate our epigenome [54].

One way of prospectively confirming the hypothesis in this paper would be to use 'knockout' mice predisposed to diabetes and see if increasing or decreasing UVR exposure in the early days of gestation (for mice, possibly as little as a 2-day exposure out of a 19-day gestation) to see if the expression of diabetes occurs earlier or later in the animal's lifetime. Using UVR to treat humans with a genetic predisposition to diabetes must await the results of prospective animal studies along with an increased knowledge of our epigenome [55].

\section{Conclusions}

The significant findings of this research are summarized as follows:

- The effects of UVR modulate human lifespan in diabetics; for example, both solar and seasonal cycles affect the human epigenome. We believe that UVR has a more profound effect at conception/ early 
gestation, but may still affect adults, albeit more weakly as in seasonal affective disorder when an increased appetite and weight gain can be a problem.

- The difference between lifespan at MAX and MIN serves as a surrogate for sensitivity (or responsiveness) to long-term variation in UVR. The differences in lifespan between months would analogously apply for short-term variation.

- Ethnic minority diabetics, who were born before the year 1945, lived slightly longer than non-diabetics of the same period. Our data analysis supports the hypothesis that epigenetic effects that conserve energy benefit survival in persons living with marginal nutrition and exposed to hard physical labor.

- Diabetic women have canalized metabolic conservation more effectively than men, primarily for fertility/pregnancy, and are less affected by UVR than men, but consequently are more susceptible to weight gain in times of surfeit.

- The hypothesis that we might modulate the phenotypic expression of type-2 diabetes by using UVR; for example, optogenetics, is eminently testable.

- Other forces associated with our variable star, like geomagnetic fields, may also be playing a role in modulating our epigenome and are areas for future research.

\section{Methods \\ Data}

Data were obtained from the National Center for Health Statistics (NCHS) for deaths in all 50 states and the District of Columbia from 1979 to 2005 - a total of $58,733,243$ deaths. The data were de-identified to preserve confidentiality with only month and year of birth obtained. Data used in this study included sex, state of birth, date of birth (month and year), date of death (month and year), and race. Since data on Hispanic origin was not recorded from 1979 to 1988, race categories used for this study included white, African-American, NativeAmerican/Alaska Native, Asian/Pacific Islander races. White Canadians in the study were born in Canada but lived and died in the United States. From 1989 to 2005 we had access to a Mexican (Hispanic) cohort. These were persons born largely in Mexico but lived and died in the United States. For this study the white race $(\mathrm{N}=$ $50,778,214)$ was the largest group. The sample contained $51 \%$ males and $49 \%$ females. Approximately $90 \%$ of the persons in the database were born in or before the year 1945 and would have died between 1979 and 2005. The average age at death was 71 . We did not age match controls, but given the sample size, and by randomization, we derived a reasonable control set. The persons in our database lived in challenging times, which included a Great
Depression occurring between two World Wars in an agrarian/ industrial economy.

\section{Solar data}

The Sun is a variable star which varies its electromagnetic and plasma energy output in an approximate 11year cycle (varying 9 to 14 years). A measure of this energy output is the sunspot number. Sunspots are magnetic storms on the Sun's surface that indicate increased fusion activity and their number correlates positively with the intensity of solar radiation including ultraviolet wavelengths. UVR is an important source of Earth's energy and despite that only 1 percent of the sun's energy is emitted at UVR wavelengths between 200 and 300 $\mathrm{nm}$, UVR accounts for nearly 20 percent of the variation in total irradiance. A recent study revealed that a $5 \%$ variation in ground-level UVR (though not related to solar cycles) produces a $24 \%$ variation in effects on DNA [56-59]. The average annual number of sunspots was collected from the NOAA (National Oceanic and Atmospheric Administration) Web site and the three MAX years (approximately 28\%) of each of the past twelve cycles was obtained to be compared with the remaining MIN years (approximately 72\%) [60]. The average annual sunspot number for the past 250 years was found to be 49; for the past 60 years the average is 107.5 ; for the most powerful cycles (sunspots $>135$ ), the average is 154 , about three times the 250-year average. The time period of our study comprised 13 solar cycles [25].

\section{Statistical methodology}

Birth year data were grouped by solar MAX or MIN and were defined as follows: the year before and the year after the peak years were defined as the Maximum Solar Period (MAX); the years before and after each three-year MAX cycle were grouped as Minimum Solar Period (MIN). We selected diabetics using ICD-9 codes recorded as cause of death. Total diabetics plus non-diabetics equaled approximately 54 million, of which $28 \%$ were in the MAX group, which equaled approximately 15 million cases Diabetics accounted for $1.5 \%$ of the total all-racial set, and those born in a MAX period accounted for 226,442 diabetics. These were matched with an equal number of randomly selected non-diabetics for further analysis, serving as control. Table 6 is an example of the white race from Additional file 2: Appendix 1 (Table S1 -S6) and gives lifespan statistics for diabetics and non-diabetics by bimonthly groups. Table 7 lists the statistics of each racial group. Table 8 lists the total of diabetics and non-diabetics by racial group.

In this paper we report both birth and conception months and we consider the month of conception to be 10 months (approximately 39 weeks) earlier than birth month. We frequently refer to conception months as we 
Table 6 Displays an example from Additional file 2: Appendix 1 for two bimonthly periods for increasing UVR at conception and for decreasing UVR at conception for the white race (a similar analysis was done for all 12 bimonthly sets for each racial group

\begin{tabular}{|c|c|c|}
\hline White & Average MAX-MIN & Average MAX-MIN \\
\hline & July-August Births (years) & November-December Births (years) \\
\hline All male & -3.167 & -3.141 \\
\hline (White) & avg $^{a}$ age MAX: & avg age MAX: \\
\hline \multirow[t]{7}{*}{ Non-diabetic } & 67.4 & 67.8 \\
\hline & avg age at MIN: & avg age at MIN: \\
\hline & 70.6 & 71.0 \\
\hline & $\mathrm{n} \max =815,000$ & $n \max =756,000$ \\
\hline & $\mathrm{n} \min =795,000$ & $\mathrm{n} \min =726,000$ \\
\hline & standard error $=0.03$ & standard error $=0.03$ \\
\hline & $p<0.0001$ & $p<0.0001$ \\
\hline All female & -2.479 & -2.360 \\
\hline \multirow[t]{8}{*}{ Non-diabetic } & avg age MAX: & avg age MAX: \\
\hline & 74.7 & 75.2 \\
\hline & avg age at MIN: & avg age at MIN: \\
\hline & 77.2 & 77.5 \\
\hline & $\mathrm{n} \max =759,000$ & $\mathrm{n} \max =708,000$ \\
\hline & $\mathrm{n} \min =796,000$ & $\mathrm{n} \min =730,000$ \\
\hline & standard error $=0.03$ & standard error $=0.03$ \\
\hline & $p<0.0001$ & $p<0.0001$ \\
\hline \multirow[t]{9}{*}{ Diabetic male } & -2.610 & -2.057 \\
\hline & avg age MAX: & avg age MAX: \\
\hline & 68.7 & 69.6 \\
\hline & avg age at MIN: & avg age at MIN: \\
\hline & 71.3 & 71.6 \\
\hline & $\mathrm{n} \max =9,756$ & $n \max =9,117$ \\
\hline & $\mathrm{n} \min =9,783$ & $\mathrm{n} \min =9,150$ \\
\hline & standard error $=0.19$ & standard error $=0.20$ \\
\hline & $p<0.0001$ & $p<0.0001$ \\
\hline \multirow[t]{9}{*}{ Diabetic female } & -2.074 & -1.789 \\
\hline & avg age MAX: & avg age MAX: \\
\hline & 73.6 & 74.0 \\
\hline & avg age at MIN: & avg age at MIN: \\
\hline & 75.4 & 75.8 \\
\hline & $\mathrm{n} \max =11,493$ & $\mathrm{n} \max =11,053$ \\
\hline & $\mathrm{n} \min =12,391$ & $\mathrm{n} \min =11,936$ \\
\hline & standard error $=0.16$ & standard error $=0.17$ \\
\hline & $p<0.0001$ & $p<0.0001$ \\
\hline Equivalent months of conception & OCT-NOV (decreasing UVR) & FEB-MAR (increasing UVR) \\
\hline
\end{tabular}

\footnotetext{
avg, average; abbr, abbreviation defined
} 
Table 7 Sample total by race

\begin{tabular}{|c|c|c|c|c|c|}
\hline Race & Count & Percent & Mean age & SD & Median age \\
\hline White & $45,714,048$ & 84.1 & 71.9 & 18.6 & 76 \\
\hline White (Canadian) & 450,760 & 0.8 & 78.5 & 13.4 & 81 \\
\hline African-American & $6,747,125$ & 12.4 & 62.1 & 23.1 & 67 \\
\hline Asian & 672,286 & 1.2 & 66.2 & 22.3 & 72 \\
\hline Native American & 249,169 & 0.5 & 57.3 & 24.5 & 62 \\
\hline Hispanic (Mexican) & 532,151 & 1.0 & 63.4 & 23.3 & 69 \\
\hline Totals & $53,914,779$ & 100 & 70.5 & & 75 \\
\hline
\end{tabular}

believe that the conceptus is more sensitive to the effects of environmental UVR than at the time of birth.

\section{Data analysis}

We subtracted the age-at-death of non-diabetics from the age-at-death of diabetics for all races for months of conception (10 months earlier than months of birth), and for both genders for MAX and MIN of solar cycles. These data, derived from Additional file 2: Appendix 1 (which only shows a single bimonthly sample out of a full year of data), are displayed in Additional file 1: Appendix 2 [see Table S1-S6]. The data from Additional file 1: Appendix 2 were then plotted for each set of months (bimonthly to increase N), MAX on the Y-axis, MIN on the X-axis (see Figures 2 and 3). Regression equations were calculated by Excel and were integrated with Mathematica version 7.0 from -5.0 to 10.0 years (a reasonable range seen in the regressions) to calculate the overall number of years of life gained (or lost) by diabetics over non-diabetics. We performed this procedure for both MAX and MIN (by reversing the axes) and the results of lifespan years gained or lost are displayed in Tables 1 and 2 in the 3rd and 5th columns. The high $\mathrm{R}^{2}$ (all 24 equations, 12 for MAX and 12 for MIN, was >0.90) suggests a strong relationship between radiant energy at MAX and MIN and the lifespan difference between diabetics and non-diabetics. The integrals of the linear regression lines from Tables 1 and 2 were plotted on the Y-axis with months of conception on the $\mathrm{X}$-axis, for MAX and MIN and for males and females as shown in Figure 4.

When months of the year with increasing light are compared with those months with decreasing at both MAX and MIN, we must take into account that the solstices occur about 10 days (approximately 16\% of a twomonth period) before the end of the month. Further calculations were performed using the data from Tables 1 and 2, an example of which follows for the MAX portion of solar cycles:

Diabetic Males at MAX in increasing UVR: (0.16) $($ Dec-Jan $)+($ Jan-Feb $)+($ Feb-Mar $)+($ Mar-Apr $)+($ AprMay $)+(0.84)($ May-Jun $)=(0.16)(37.1)+(41.4)+59.5+$ $43.9+47.8+(0.84)(51.5)=241.8$ years
The Table 3 summarizes calculations of integral years gained by diabetics. Table 4 shows the calculations using the data in Table 3.

Since MIN comprises approximately $72 \%$ of a solar cycle and MAX approximately $28 \%$, then a weighted average using values from Table 4:

Male $/$ Female diabetic ratio $=(0.72)(1.52)+(0.28)$ $(0.72)=1.09+0.20=\mathbf{1 . 3 0}$ for decreasing UVR

Similarly,

Male/ Female diabetic ratio $=(0.72)(1.05)+(0.28)$ $(0.96)=0.76+0.27=\mathbf{1 . 0 2}$ for increasing UVR

Therefore, the male/female ratio of years gained by diabetics in decreasing UVR/ increasing UVR $=1.30$ / $1.02=\mathbf{1 . 2 7}$

Note that the above ratios indicate relative effects and do not translate directly to differences in lifespan as measured in years.

\section{Ethics statement}

As the data obtained were de-identified, and as there were no direct therapeutic interventions of persons, we declare no ethical conflicts in our study.

\section{Study strengths}

The large death records database from the entire United States gives high statistical power. We did not have to use life expectancy tables as we had the actual time of birth and death of each case.

Table 8 Total diabetics and non-diabetics by racial group

\begin{tabular}{|c|c|c|}
\hline Race & Count of diabetics & Count of non-diabetics \\
\hline White & 646,808 & $45,070,000$ \\
\hline African-American & 146,598 & $6,600,290$ \\
\hline Native American & 6,951 & 242,208 \\
\hline Asian & 9,903 & 662,383 \\
\hline White Canadian & 5,766 & 444,993 \\
\hline Mexican & 12,705 & 519,430 \\
\hline Totals & 828,731 & $53,539,304^{\mathrm{a}}$ \\
\hline
\end{tabular}

${ }^{\mathrm{a}}$ The totals in Tables 7 and 8 do not agree by $0.84 \%$ due to the fact that in some cases diagnosis was not recorded. 


\section{Study limitations}

The use of death certificates by the database for diagnosis is a limitation in this study. However, as stated previously, those listed as diabetic were the most seriously afflicted so the diagnosis would probably not be in doubt. The small number of type- 1 diabetics (usually approximately 5 to $10 \%$ ) mixed in the sample would not significantly alter our conclusions.

\section{How this study contributes to new knowledge}

We believe this study supports the effect of UVR in modulating the human epigenome in type- 2 diabetes.

\section{Additional files}

\section{Additional file 1: Appendix 2 (A): RESULTS for MALES of Step 1 in} Sequence of analysis [diabetic minus non-diabetic lifespan]. MOC = month of conception; $M O B=$ month of birth. (B): RESULTS for FEMALES of Step 1 in Sequence of analysis [diabetic minus non-diabetic lifespan]. $\mathrm{MOC}=$ month of conception; $\mathrm{MOB}=$ month of birth

Additional file 2: Appendix 1. Table S1 [MAX - MIN] for White Nondiabetics \& Diabetics by Increasing or Decreasing light at Birth (or Conception). Table S2: [MAX - MIN] for Asian Non-diabetics \& Diabetics by Increasing or Decreasing light at Birth (or Conception). Table S3: [MAX - MIN] for White (Canadian) Non-diabetics \& Diabetics by Increasing or Decreasing light at Birth (or Conception). Table S4: [MAX MIN] for Hispanic Non-diabetics \& Diabetics by Increasing or Decreasing light at Birth (or Conception). Table S5: [MAX - MIN] for AfricanAmerican Non-diabetics \& Diabetics by Increasing or Decreasing light at Birth (or Conception). Table S6: [MAX - MIN] for Native American Nondiabetics \& Diabetics by Increasing or Decreasing light at Birth (or Conception)

\section{Abbreviations}

MOB: month of birth; MOC: month of conception; MAX: peak of solar cycle: MIN: trough of solar cycle; UVR: ultraviolet radiation.

\section{Competing interests}

The authors declare that they have no competing interests.

\section{Authors' contributions}

The authors contributed equally to this work. GED wrote the manuscript, WEL analyzed the data and performed statistical work. All authors read and approved the final manuscript.

\section{Acknowledgements}

We would like to thank the National Center for Healthcare Statistics and Arialdi Minino, MPH, demographer/ statistician at the NCHS, for his help in obtaining the primary database for this study.

\section{Received: 19 August 2012 Accepted: 11 March 2013} Published: 2 April 2013

\section{References}

1. Prentice AM: Obesity in emerging nations: evolutionary origins and the impact of a rapid nutrition transition. Nestle Nutr Workshop Ser Pediatr Program 2009, 63:47-54. discussion 54-47, 259-268.

2. Semba RD, Bloem MW: Nutrition and health in developing countries. Totowa, NJ: Humana Press; 2008.

3. Yang W, Lu J, Weng J, Jia W, Ji L, Xiao J, Shan Z, Liu J, Tian H, Ji Q, Zhu D, Ge J, Lin L, Chen L, Guo X, Zhao Z, Li Q, Zhou Z, Shan G, He J, China National Diabetes and Metabolic Disorders Study Group: Prevalence of diabetes among men and women in China. N Engl J Med 2010, 362:1090-1101.

4. Ling C, Groop L: Epigenetics: a molecular link between environmental factors and type 2 diabetes. Diabetes 2009, 58:2718-2725.
5. Francis RC: Epigenetics-the ultimate mystery of inheritance. New York: W. W. Norton \& Company, Inc.; 2011.

6. Berletch JB, Yang F, Disteche CM: Escape from $\mathrm{X}$ inactivation in mice and humans. Genome Biol 2010, 11:213.

7. Wadhwa PD, Buss C, Entringer S, Swanson JM: Developmental origins of health and disease: brief history of the approach and current focus on epigenetic mechanisms. Semin Reprod Med 2009, 27:358-368.

8. Tang WY, Ho SM: Epigenetic reprogramming and imprinting in origins of disease. Rev Endocr Metab Disord 2007, 8:173-182.

9. Stoger R: Epigenetics and obesity. Pharmacogenomics 2008, 9:1851-1860

10. Fradin D, Bougneres P: T2DM: Why Epigenetics? J Nutr Metab 2011, 2011:647514.

11. Xu XF, Du LZ: Epigenetics in neonatal diseases. Chin Med J (Engl) 2010, 123:2948-2954.

12. Pollin TI: Epigenetics and diabetes risk: not just for imprinting anymore? Diabetes 2011, 60:1859-1860.

13. Salbaum JM, Kappen C: Diabetic embryopathy: a role for the epigenome? Birth Defects Res A Clin Mol Teratol 2011, 91:770-780.

14. Gluckman PD, Hanson MA, Cooper C, Thornburg KL: Effect of in utero and early-life conditions on adult health and disease. N Engl J Med 2008, 359:61-73.

15. Fernandez-Morera JL, Rodriguez-Rodero S, Menendez-Torre E, Fraga MF: The possible role of epigenetics in gestational diabetes: cause, consequence, or both. Obstet Gynecol Int 2010, 2010:605163.

16. Gluckman PD, Hanson MA, Spencer HG, Bateson P: Environmental influences during development and their later consequences for health and disease: implications for the interpretation of empirical studies. Proc Biol Sci 2005, 272:671-677.

17. Dolinoy DC, Jirtle RL: Environmental epigenomics in human health and disease. Environ Mol Mutagen 2008, 49:4-8.

18. Pembrey ME, Bygren LO, Kaati G, Edvinsson S, Northstone K, Sjostrom M, Golding J: Sex-specific, male-line transgenerational responses in humans. Eur J Hum Genet 2006, 14:159-166.

19. Kaati G, Bygren LO, Pembrey M, Sjostrom M: Transgenerational response to nutrition, early life circumstances and longevity. Eur J Hum Genet 2007, 15:784-790.

20. Huang ES, Basu A, O'Grady M, Capretta JC: Projecting the future diabetes population size and related costs for the U.S. Diabetes Care 2009, 32:2225-2229.

21. Taubes G: Insulin resistance. Prosperity's plague. Science 2009, 325:256-260.

22. Davis GE Jr, Lowell WE: The Sun determines human longevity: teratogenic effects of chaotic solar radiation. Medical Hypotheses 2004, 63:574-581.

23. Lowell WE, Davis GE Jr: The effect of solar cycles on human lifespan in the 50 United States: variation in light affects the human genome. Medical Hypotheses 2010, 75:17-25.

24. Diffey BL: Solar ultraviolet radiation effects on biological systems. Phys Med Biol 1991, 36:299-328.

25. Davis GE Jr, Lowell WE: Chaotic solar cycles modulate the incidence and severity of mental illness. Med Hypotheses 2004, 62:207-214.

26. Davis GE Jr, Lowell WE: Solar cycles and their relationship to human disease and adaptability. Med Hypotheses 2006, 67:447-461.

27. Schell LM, Gallo MV: Overweight and obesity among North American Indian infants, children, and youth. Am J Hum Biol 2012, 24:302-313.

28. Lane RW: The Discovery of Freedom. New York: The John Day Company; 1943.

29. Centers for Disease Control: Achievements in Public Health, 1900-1999: Safer and Healthier foods-Morbidity \& Mortality Weekly Report.. www.cdc.gov/ $\mathrm{mmwr} / \mathrm{preview} / \mathrm{mmwrhtml} / \mathrm{mm} 4840 \mathrm{a} 1 . \mathrm{htm}$

30. Harrison GA: Famine. New York, USA: Oxford University Press; 1988

31. Greenhough PR: Prosperity and Misery in Modern Bengal: the famine of 1943-1944. New York: Oxford University Press: 1982

32. Dikotter F: Mao's Great Famine. New York: Walter Books; 2010.

33. Ganson N: The Soviet Famine of 1946-47 in global and Historical Perspective. New York: Palgrave Macmillan; 2009.

34. Hinshaw J, LeBlanc P: U. S. labor in the twentieth century: studies in workingclass struggles and insurgency. Amherst, New York: Humanity Books; 2000.

35. The Struggles of Labor.. http://countrystudies.us/united-states/history-82.htm.

36. Scott EM, Grant PJ: Neel revisited: the adipocyte, seasonality and type 2 diabetes. Diabetologia 2006, 49:1462-1466.

37. Vaiserman AM, Khalangot MD, Carstensen B, Tronko MD, Kravchenko VI, Voitenko VP, Mechova LV, Koshel NM, Grigoriev PE: Seasonality of birth in adult type 2 diabetic patients in three Ukrainian regions. Diabetologia 2009, 52:2665-2667. 
38. Slominski AT, Zmijewski MA, Skobowiat C, Zbytek B, Slominski RM, Steketee JD: Sensing the environment: regulation of local and global homeostasis by the skin's neuroendocrine system. Adv Anat Embryol Cell Biol 2012, 212:1-115. v, vii.

39. Juzeniene A, Moan J: Beneficial effects of UV radiation other than via vitamin D production. Dermatoendocrinology 2012, 4:109-117.

40. Kostyuk V, Potapovich A, Stancato A, De Luca C, Lulli D, Pastore S, Korkina L: Photo-oxidation products of skin surface squalene mediate metabolic and inflammatory responses to solar UV in human keratinocytes. PLOS One 2012, 7(8):e44472.

41. Liu W, Wu S: Differential roles of nitric oxide synthases in regulation of ultraviolet B light-induced apoptosis. Nitric Oxide 2010, 23:199-205.

42. Chagas CE, Borges MC, Martini LA, Rogero MM: Focus on vitamin D, inflammation and type 2 diabetes. Nutrients 2012, 4:52-67.

43. Takiishi T, Gysemans C, Bouillon R, Mathieu C: Vitamin d and diabetes. Rheum Dis Clin North Am 2012, 38:179-206.

44. Nwosu BU, Stavre ZG, Maranda L, Cullen K, Lee MM: Hepatic dysfunction is associated with vitamin $D$ deficiency and poor glycemic control in diabetes mellitus. J Pediatr Endocrinol Metab 2012, 25:181-186.

45. Shaban LH, Zarini GG, Exebio JC, Sukhram SD, Huffman FG: Serum Vitamin D Insufficiency and Diabetes Status in Three Ethnic Minority Groups. J Immigr Minor Health 2012, 14:926-932.

46. Talaei A, Mohamadi M, Adgi Z: The effect of vitamin D on insulin resistance in patients with type 2 diabetes. Diabetol Metab Syndr 2013, 5:8.

47. Hossein-nezhad A, Holick MF: Optimize dietary intake of vitamin D: an epigenetic perspective. Curr Opin Clin Nutr Metab Care 2012, 15:567-579.

48. Kaseta JR, Skafar DF, Ram JL, Jacober SJ, Sowers JR: Cardiovascular disease in the diabetic woman. J Clin Endocrinol Metab 1999, 84:1835-1838.

49. Kelly C, Booth GL: Diabetes in Canadian Women. BMC Womens Health 2004, 4(Suppl 1):S16.

50. Lane N: Oxygen-the molecule that made the world. reprint of the 2002 edition. New York: Oxford University Press; 2009.

51. Baschetti R: Diabetes epidemic in newly westernized populations: is it due to thrifty genes or to genetically unknown foods? J R Soc Med 1998, 91:622-625.

52. Prentice AM, Moore SE: Early programming of adult diseases in resource poor countries. Arch Dis Child 2005, 90:429-432.

53. Jayaweera $H$, Quigley MA: Health status, health behaviour and healthcare use among migrants in the UK: evidence from mothers in the Millennium Cohort Study. Soc Sci Med 2010, 71:1002-1010.

54. Close J: Are stress responses to geomagnetic storms mediated by the cryptochrome compass system? Proc Biol Sci 2012, 279:2081-2090.

55. Deisseroth K: Optogenetics. Nat Methods 2011, 8:26-29.

56. Lean J: Contribution of ultraviolet irradiance variations to changes in the sun's total irradiance. Science 1989, 244:197-200.

57. Lean J: Detection and parameterization of variations in solar mid- and nearultraviolet radiation (200-400 nm). J Geophys Res 1997, 102:29,939-929,956.

58. Lean J: Living with a variable sun. Physics Today 2005, 58:32-38.

59. Petkov B, Vitale V, Tomasi C, Mazzola M, Lanconelli C, Lupi A, Busetto M: Variations in total ozone column and biologically effective solar UV exposure doses in Bologna, Italy during the period 2005-2010. Int Biometeorol 2013. Epub ahead of print.

60. Index of /STP/SOLAR_DATA/.ftp://ftp.ngdc.noaa.gov/STP/SOLAR_DATA/ SUNSPOT_NUMBERS/GROUP_SUNSPOT_NUMBERS/monthrg.dat.

doi:10.1186/1868-7083-5-5

Cite this article as: Davis and Lowell: Variation in ultraviolet radiation and diabetes: evidence of an epigenetic effect that modulates diabetics' lifespan. Clinical Epigenetics 2013 5:5.

\section{Submit your next manuscript to BioMed Central and take full advantage of:}

- Convenient online submission

- Thorough peer review

- No space constraints or color figure charges

- Immediate publication on acceptance

- Inclusion in PubMed, CAS, Scopus and Google Scholar

- Research which is freely available for redistribution

Submit your manuscript at www.biomedcentral.com/submit
C) Biomed Central 